Research article

urn:lsid:zoobank.org:pub:8F998964-785F-489C-836C-65D56B6CDED4

\title{
A revision of Ichneumonopsis Hardy, 1973 (Diptera: Tephritidae: Dacinae: Gastrozonini), Oriental bamboo-shoot fruit flies
}

\author{
Amnon FREIDBERG ${ }^{1}$, Damir KOVAC ${ }^{2,{ }^{*}} \&$ Shiuh-Feng SHIAO ${ }^{3}$ \\ ${ }^{1}$ The Steinhardt Museum of Natural History, Israel National Center for Biodiversity Studies, \\ Department of Zoology, The George S. Wise Faculty of Life Sciences, \\ Tel Aviv University, Tel Aviv 69978, Israel. \\ ${ }^{2}$ Forschungsinstitut Senckenberg, Senckenberganlage 25, D-60325 Frankfurt am Main, Germany. \\ ${ }^{3}$ Department of Entomology, National Taiwan University 27, Lane 113, \\ Roosevelt Rd. Sec. 4, Taipei, Taiwan, 106. \\ *Corresponding author: damir.kovac@senckenberg.de \\ ${ }^{1}$ Email: afdipter@post.tau.ac.i1 \\ ${ }^{3}$ Email: sfshiao@ntu.edu.tw \\ ${ }^{1}$ urn:1sid:zoobank.org:author:7687F3A8-39F4-44A8-8C66-1E4A5B372A9E \\ ${ }^{2}$ urn:lsid:zoobank.org:author:8621C8FD-0A44-423E-8B74-A314B473F456 \\ ${ }^{3}$ urn:lsid:zoobank.org:author:E885C52C-5401-496E-96DE-DE12B2B7B8AE
}

\begin{abstract}
Ichneumonopsis Hardy,1973, a genus of oriental fruit flies, is revised and two new species, I. hancocki sp. nov. (from Peninsular Malaysia) and I. taiwanensis sp. nov. (from Taiwan), are described. A key to the three species of Ichneumonopsis is presented. In northern Thailand larvae of I. burmensis Hardy, 1973 develop in bamboo shoots of Pseudoxytenanthera albociliata (Munro) Nguyen and Dendrocalamus strictus (Roxburgh) Nees (Poaceae), not Melocalamus compactiflorus as previously reported. The recently discovered association of I. burmensis with bamboo substantiates our previous assumption assigning Ichneumonopsis to the primarily bamboo-inhabiting tribe Gastrozonini. Hence, we synonymize Ichneumonopsidini under Gastrozonini (syn. nov.).
\end{abstract}

Keywords. New species, new records, distribution, key, bamboo, Pseudoxytenanthera.

Freidberg A., Kovac D. \& Shiao S.-F.2017. A revision of Ichneumonopsis Hardy, 1973 (Diptera: Tephritidae: Dacinae: Gastrozonini), Oriental bamboo-shoot fruit flies. European Journal of Taxonomy 317: 1-23. https://doi. org/10.5852/ejt.2017.317

\section{Introduction}

Hardy (1973: 132) erected the monobasic genus Ichneumonopsis, with I. burmensis as the type species, based on a single male and female collected in the Chin Hills, Myanmar (Burma). He placed Ichneumonopsis in the Adramini (Subfamily Trypetinae) because of the reduced cephalic and thoracic chaetotaxy. Hancock (1986) noted that Ichneumonopsis differed from typical Adramini by the absence of long hairs on the laterotergite, by having "a narrow anal cell extension" and by having only two 
spermathecae in the female. He argued that these characters, combined with the wing pattern and the general reduction of head setae, suggested a relationship with the Dacinae. He considered Ichneumonopsis the most primitive genus of the subfamily Dacinae and erected a new tribe, Ichneumonopsidini, with Ichneumonopsis as its type and only genus. Drew \& Hancock (1994) redescribed Ichneumonopsis and presented an updated diagnosis for the genus, retaining it in the Dacinae in the narrow sense (i.e., together with Dacus Fabricius, 1805, Bactrocera Macquart, 1835 and Monacrosticus Bezzi, 1914).

Norrbom et al. (1999a: 21) found that Ichneumonopsis lacked the synapomorphies of the Dacini in the narrow sense (as Dacina in Norrbom et al. 1999a), i.e., the posterodistal lobe of cell bcu was only moderately long and the spermathecae rounded (in Dacini the posterodistal lobe of cell bcu is usually very long and the spermathecae are mulberry-like). They tentatively placed Ichneumonopsis in the Gastrozonini (as Gastrozonina in Norrbom et al. 1999a) based on its short plumose arista and broad aculeus. Kovac et al. (2006), in their catalogue of Gastrozonini, retained Ichneumonopsis in the Gastrozonini based on the same characters, although no host or other records that could support this decision were available at that time.

Since all reared Oriental Gastrozonini to date have been reared from bamboo (Hancock \& Drew 1999 and subsequent authors), and all reared Afrotropical Gastrozonini have been reared from Poaceae (Hancock 1999; Copeland 2007), host relationships probably provide the best synapomorphy for this group. Kovac et al. (2013) reported that I. burmensis, a species that is known from Myanmar, India and north Thailand (Radhakrishnan 2000; Kovac et al. 2013) and is very rare in collections, is associated with bamboo, indicating that Ichneumonopsis belongs to the primarily bamboo-inhabiting tribe Gastrozonini. Nevertheless, Drew \& Romig (2013) continued to treat Ichneumonopsis as a Dacini, albeit without explanation.

In the present paper we redescribe the genus Ichneumonopsis and its type species I. burmensis, for which we also provide precise information on distribution, beyond the data provided by Kovac et al. (2013). We also describe I. hancocki sp. nov. from Peninsular Malaysia and I. taiwanensis sp. nov. from Taiwan. The recent rearing of I. burmensis from bamboo for the first time (Kovac et al. 2013) has substantiated our previous assumption assigning Ichneumonopsis to the primarily bamboo-inhabiting tribe. Therefore, we synonymize here Ichneumonopsidini under Gastrozonini (syn. nov.), and, at least from our point of view, the current tribal assignment of Ichneumonopsis now stands on a firm basis.

\section{Material and methods}

Field collecting and observations on I. burmensis Hardy, 1973 were conducted in India (Meghalaya) in 1980 (A. Freidberg), in Taiwan in 2000 (C.Y. Lee) and in north-west Thailand between 2008 and 2013 (D. Kovac and A. Freidberg). Three general collecting methods were used: in India adult specimens were collected using a sweep net; in Thailand adults were reared from immature stages collected from the host plants; in Taiwan adult specimens were collected by using colour traps. Ichneumonopsis larvae were bred from bamboo shoot internodes of Pseudoxytenanthera albociliata (Munro) Nguyen (in Kovac et al. 2013 this bamboo was misidentified as Melocalamus compactiflorus (Kurz) Bentham) and from thin shoots of Dendrocalamus strictus (Roxburgh) Nees. Bamboo shoots suspected to contain larvae of Ichneumonopsis burmensis were cut off, transferred to the laboratory and inspected for larvae. Internodes containing larvae of $I$. burmensis were partly enwrapped with moist tissue and kept in plastic containers. Puparia were transferred to separate containers equipped with moist tissue.

Measurements are based on three specimens whenever available. Terminology follows McAlpine (1981) and White et al. (1999). Specimens, including type specimens, are deposited in the following collections (curator's name in parentheses): 


$$
\begin{array}{ll}
\text { BMNH } & \text { Natural History Museum, London, UK (Mr N. Wyatt) } \\
\text { CAS } & \text { California Academy Scientific Collections, San Francisco, California, USA (Dr B. Fisher) } \\
\text { SMF } & =\text { Senckenberg Museum, Frankfurt am Main, Germany (Dr D. Kovac) } \\
\text { SMNHTAU } & \text { Steinhardt Museum of Natural History, Tel Aviv University, Tel Aviv, Israel (Dr N. Dorchin) } \\
\text { NTU } & =\text { National Taiwan University (Dr S.-F. Shiao) }
\end{array}
$$

\title{
Results
}

\author{
Phylum Arthropoda Siebold, 1848 \\ Class Insecta Linnaeus, 1758 \\ Order Diptera Linnaeus, 1758 \\ Family Tephritidae Macquart, 1835 \\ Subfamily Dacinae Schiner, 1864 \\ Tribe Gastrozonini Hering, 1947
}

Genus Ichneumonopsis Hardy, 1973

Ichneumonopsis Hardy, 1973: 132; type species Ichneumonopsis burmensis Hardy, 1973: 133 (by original designation and monotypy).

Ichneumonopsis - Hardy 1986: 54, 56 (key to Adramini genera). — Drew \& Hancock 1994: 829 (redescription). - Drew \& Romig 2013: 403 (South-East Asian fruit flies). — Norrbom et al. 1999b: 161. — Radhakrishnan 2000: 203 (first record for India). — Kovac et al. 2006: 170 (key to Gastrozonini genera), 184. — Kovac et al. 2013: 201 (biology and immature stages).

\section{Diagnosis}

Species of this genus are large, slender and somewhat atypical Gastrozonini that cannot be readily associated with any of the other included genera due to some apomorphic characters that obscure their true relationships. The three included species bear some superficial resemblance to Enicoptera gigantea Enderlein, 1911, which is even larger, but Enicoptera Macquart, 1848 clearly differs from all other Gastrozonini genera, including Ichneumonopsis, in the peculiar and unique wing venation, e.g., it is characterized by veins $R_{1}$ and $R_{2+3}$ joining each other for a short distance just before meeting the costa.

Having several conspicuous autapomorphies, Ichneumonopsis is so distinctive that in Hardy's (1973: 76) key to Trypetinae genera (including 50 genera), it keys out in just four steps (couplets 1, 2, 46 and 47). The original description itself is rather brief, dealing almost entirely with key characters that have weak relevance here since they refer to adramine genera. In any case, Hardy's (1973: 132) assignment of Ichneumonopsis to the Adramini is clearly incorrect.

Kovac et al. (2006: 170) included Ichneumonopsis in their key to Gastrozonini, which treats 27 genera, but Ichneumonopsis keyed out in couplet 1 . The characters used in this key, although based only on the type species, can be viewed as the minimum information for a diagnosis of Ichneumonopsis within the Gastrozonini. They are: "Extremely wasp-like species, with petiolate abdomen, spinose forefemur and dimidiate wing pattern; chaetotaxy reduced: one (but updated to 0-2 in the Redescription below) setulalike frontal seta, one small orbital seta and one scutellar seta present; ocellar, dorsocentral, acrostichal, intra-alar, postpronotal and pleural setae, except one anepisternal seta, lacking." The following generic description, based on the type species plus the two newly described species, incorporates all characters available from the literature plus additional characters that we think are useful in separating this genus from other Gastrozonini. 


\section{Redescription}

Extremely ichneumonid-like species, with elongate body and antennae, petiolate abdomen (Figs 20-21), contrasting dark (brown or black) and yellow or white markings on all body parts, and usually dimidiate wing pattern (anterior 0.4 of wing yellow, remaining part hyaline (Fig. 18), although in I. taiwanensis sp. nov. (Fig. 19) there are additional dark areas on posterior half of wing); sexes not conspicuously dimorphic. Chaetotaxy reduced, with many major setae lacking or small, setula-like; one pair of (apical) scutellar setae present; entire body with pale (mostly yellow, sometimes brown or blackish) setulae not strongly contrasted with background. Microtrichia indistinct.

\section{Head (Figs 5-6)}

STRUCTURE. Distinctly higher than long, with high and transversely convex face and narrow and shallow antennal fovea (groove), frons sloping, frontofacial angle about $100^{\circ}-120^{\circ}$; gena high, about 0.33 times as high as eye; occiput rather flat dorsally, swollen ventrally; antenna longer than face, with all three segments at least somewhat elongate, including scape which is distinctly porrect, with $1^{\text {st }}$ flagellomere about 4-5 times as long as high, rounded apically; arista short plumose, plumosity about as wide as $1^{\text {st }}$ flagellomere height.

Colouration. Primarily yellow, with black or blackish parts as follows: orbital plate, ocellar triangle, both sometimes united, irregular spot on anterior part of frons, genal spot, small spot laterally on face at mid-height, small spot around and ventral to base of lateral vertical seta, and long vertical spot extending over most of ventral part of occiput to genal margin, latter sometimes indistinct. In addition, face almost entirely black or with elaborate pattern of numerous small spots; these spots variable in number and expression, often asymmetrical, sometimes lacking.

Chaetotaxy and vestiture. Frontal setae 0-2, if present then small (anterior frontal) or setula-like, barely distinguishable from adjacent setulae; anterior orbital seta small but distinct; posterior orbital seta present or lacking, if present, then small, setula-like and barely distinguishable from adjacent setulae; medial and lateral vertical setae present; ocellar seta lacking; postocellar seta indistinguishable from adjacent setulae; genal seta present; postocular setae tiny, inconspicuous. Setulae mostly fine and rather sparse, more spine-like and blackish around occipital foramen.

\section{Thorax (Figs 7-9)}

StRUCtURE. Scutum narrow, length to width ratio 1.33-1.40; scutellum small, about $0.22-0.27$ times as long as scutum ( $\mathrm{n}=7$ for both ratios); clear overlap between the three species, moderately convex.

Colouration. Mostly yellow, with complex dark (brown to black) pattern. Scutum generally with five longitudinal brown to black vittae, including (single) median, (pair) dorsocentral and (pair) notopleural vittae, the latter vitta not extending along entire scutum, the former two vittae often entire, connected across posterior margin, hence scutum without distinct yellow or white prescutellar markings; postpronotal lobe mostly yellow, sometimes slightly dark (brown to black anteriorly); scutellum entirely yellow; pleural pattern complex; see description of I. burmensis for details. Subscutellum and mediotergite mostly yellow to brownish, laterally and dorsally brown.

ChaetotaXy AND vestiture. Notopleural setae 2, postsutural supra-alar, postalar, anepisternal and one pair (apical) scutellar setae present; scapular, postsutural dorsocentral and katepisternal setae present or absent, scapular setae entirely lacking in the two specimens of I. hancocki sp. nov., but present in the two other species, although median pair lacking in all specimens of I. taiwanensis sp. nov. and sometimes also in I. burmensis. Lateral pair variable in size but usually distinct in the two latter species. Presutural dorsocentral, postpronotal, acrostichal and intra-alar setae lacking, median part of scutum with 10-16, 
but usually not less than 12 rows of setulae, although in $I$. sp. nov. scutum presuturally appears to have sparser setulae.

\section{Legs (Figs 13-17)}

Structure AND Chaeotaxy. Elongate, without overt features except spinose femora in both sexes. In two species (I. burmensis and I. taiwanensis sp. nov.) only forefemur spinose, with single row of 2-5 blackish spines ventrally on distal half, and other femora without any spines or setae, only setulae, whereas in $I$. hancocki sp. nov. all femora spinose, in two rows and much more extensively; midtibia with one apicoventral spine.

Colouration. Pattern complex and variable, with legs comprising whitish, yellowish, brownish and blackish parts. In I. taiwanensis sp. nov. legs more uniformly yellow probably due to immersion in alcohol. In extremely dark specimens of $I$. burmensis dark pattern is as follows: coxae entirely or partly blackish; trochanters entirely blackish; forefemur with incomplete narrow blackish ring at base and another preapically, both slightly interrupted ventrally; foretibia blackish; foretarsus blackish except basitarsus mostly whitish, blackish only apically; midfemur with incomplete blackish ring at apical 0.4; midtibia as foretibia, and midtarsus as foretarsus; hindfemur as in forefemur, but rings broader, each about 0.33 times as long as femur; hindtibia brownish-yellow; hindtarsus as in foretarsus.

\section{Wing (Figs 18-19)}

VENATION. Longitudinal veins generally straight, not sinuous; pterostigma about 6-8 times as long as wide; posterodistal lobe of cell bcu slightly shorter than, equal to, or about 1.5 times as long as distal section of vein $\mathrm{A}_{1}+\mathrm{Cu}_{2}$; stump crossvein present in cell $\mathrm{r}_{1}$, either indicated as fold or developed as vein, more or less aligned half way between crossveins R-M and DM-Cu; crossvein R-M aligned with, or slightly basal to, middle of cell $\mathrm{dm}$; crossvein DM-Cu slightly oblique anterodistally; costal spine lacking; vein $\mathrm{R}_{4+5}$ dorsally with sparse small fine setulae to about level of crossvein DM-Cu.

PATTERN. Either dimidiate (in I. burmensis and I. hancocki sp. nov.), with anterior 0.4 of wing yellowish to brownish, with posterior margin of coloured area often brown, particularly over vein $\mathrm{R}_{4+5}$, extending posteriorly only to vein $\mathrm{R}_{4+5}$ or slightly beyond, and without spots or bands, or pattern type extended dimidiate (in I. taiwanensis sp. nov.), with additional dark spots on posterior 0.6 of wing, especially over crossvein DM-Cu and distalmost section of vein $\mathrm{M}$; cell bcu yellowish in all species.

\footnotetext{
Abdomen (Figs 20-21)

STRUCTURE. Strongly elongate, petiolate; syntergite $1+2$ about as long as remaining preabdomen, broadened posteriorly, with distal 0.2 narrowed in dorsal view; tergite 6 of female $0.2-0.3$ times as long as tergite 5; oviscape about as long as, or longer than, preabdomen, conical at basal 0.2 , remaining part cylindrical.

Colouration. Abdomen generally banded, with H-shaped or Y-shaped dark pattern on syntergite 1+2, with dark bifurcation always on $\mathrm{T} 1$, sometimes also on $\mathrm{T} 2$, posterior margin broadly yellow; remaining tergites with more or less discrete, alternating dark (usually brownish or blackish) and yellow posterior transverse bands.

Chattotaxy AND vestiture. Without obvious setae or with one or few at posterolateral corner of last tergite (both male and female), or with few setae posterolaterally on some sternites (females); syntergite $1+2$ posterolaterally with large patches of short, dense and erect minute setulae in both males and females, arranged in numerous (ca 30) rows and sometimes with longer coarse dark setulae near these (stridulatory organ?).
} 
Terminalia (based on two species)

Male (Figs 22-26)

Epandrium triangular in lateral view, with elongate surstylus, about 10 times as long as wide, and forming $140^{\circ}-160^{\circ}$ with anterior margin of epandrium; surstylus distally with digitiform prolongation more or less aligned with surstylus, about as long as surstylus width at prensisetae level; proctiger (cerci) slightly to distinctly larger than epandrium, with long and thin hair-like setae, longer, denser and darker (brownish) in one species, shorter and sparser in the other; two small prensisetae; hypandrium and ejaculatory apodeme without overt features, the latter narrow, about 3-4 times as long as wide (at widest place, near apex). Phallus about 1.1-1.2 times as long as abdomen; glans with at least four separate sclerotized plates or structures (from base to tip): first sclerite brown, rather flat dome-like at base; second sclerite opposite first sclerite but slightly more distally, yellow, flat, longer than first sclerite, comprising basal lobe; third structure at middle of glans, cochleate, the most complex and conspicuous sclerotization in the glans; finally small curved brown plate at tip of glans.

Female (Figs 27-30)

Aculeus flat, about 10 times as long as wide; cercal unit unusually wide, distinctly rounded apically, with or without constriction, with 4 preapical marginal setulae and system of straight or curved longitudinal "canals" crowded toward tip (tip of aculeus illustrated by Hardy 1973: fig. 58e) or extending more proximally; eversible membrane: with 30-40 dense rows of small yellow denticles; denticles rhomboidal, length equal to width, 209-251 $\mu \mathrm{m}$, average $230 \mu \mathrm{m}, \mathrm{n}=10$; denticles occupying basal $0.25-0.30$ of length of eversible membrane, which in most of its length lacks denticles and is translucent grey. Spermathecae - 2, spherical or almost spherical (illustrated by Hardy 1973: fig. 58c).

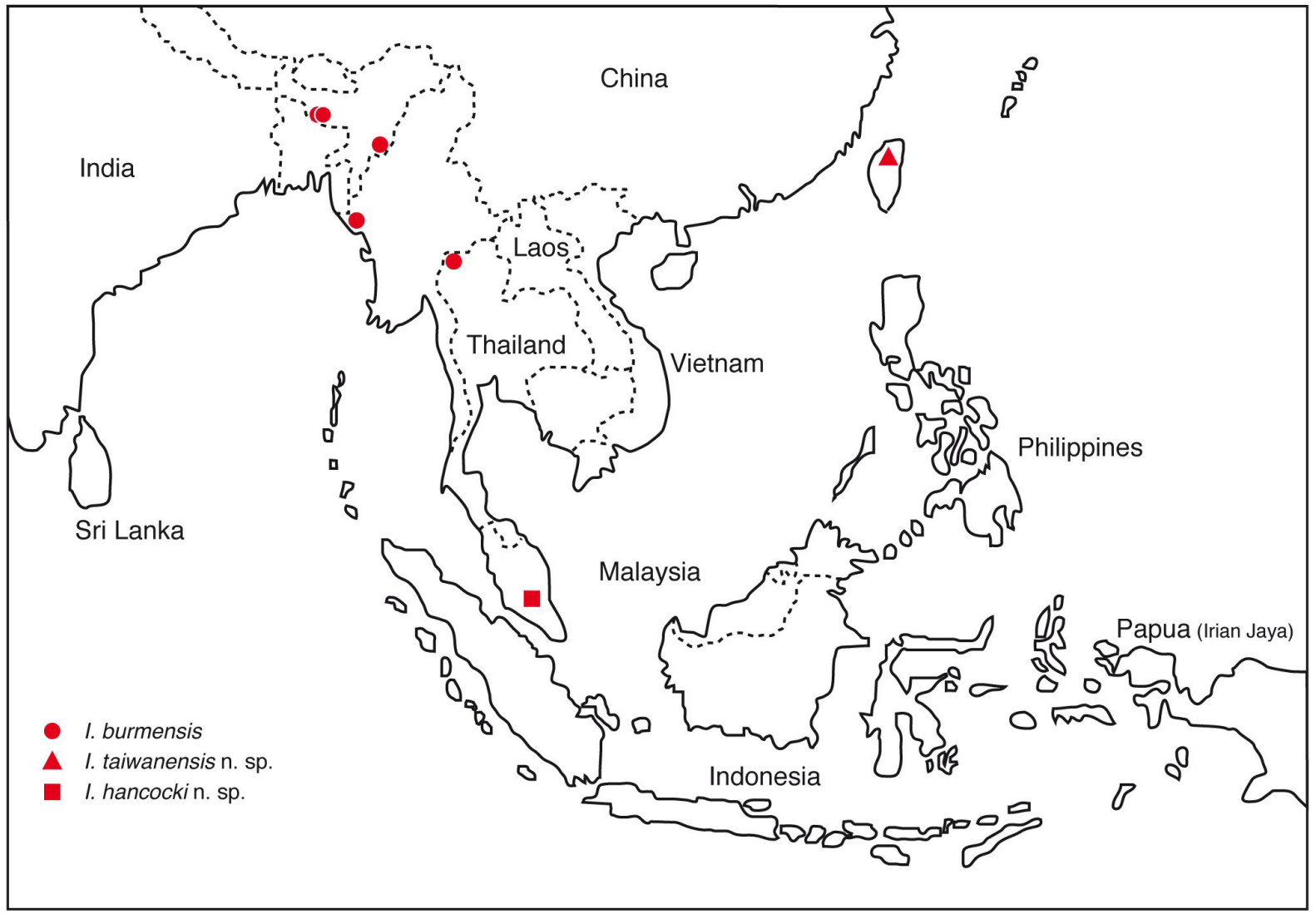

Fig. 1. Collecting localities of Ichneumonopsis spp. 


\section{Comments}

This genus has been poorly collected and documented except, perhaps, I. burmensis (Kovac et al. 2013). This situation, as well as the relative wide distribution (Fig. 1), attests to the possibility that additional species await discovery in the Oriental Region.

\section{Key to species of Ichneumonopsis}

1. Dark dorsocentral and median scutal vittae connected via two transverse bands: one at level of supraalar seta and one along scutoscutellar suture; submedian yellow vitta divided into isolated anterior vitta and posterior oval spot; all femora with rows of spines anteroventrally and posteroventrally; scapular setae absent, dorsocentral and katepisternal setae present .............hancocki sp. nov.

- Dark dorsocentral and median scutal vittae connected only via transverse band along scutoscutellar suture; submedian yellow vitta complete from anterior margin of scutum to dark transverse band along scutoscutellar suture; forefemur with about 2-5, usually 3-4, spines posteroventrally, other femora devoid of spines; scapular setae present, dorsocentral and katepisternal setae absent or dorsocentral setula-like

2. Wing pattern more extensive than dimidiate (although containing elements of the dimidiate pattern of the other species), including posteriorly: blackish bands over distalmost section of vein $\mathrm{M}$ and over crossvein $\mathrm{DM}-\mathrm{Cu}$, blackish vein $\mathrm{Cu}_{1}$ and its immediate vicinity and less discrete blackish spot over distal half of posterodistal lobe of cell bcu; remaining posterior half of wing appearing greyish or hyaline, depending on the light; spur vein (across cell $r_{1}$ ) brownish and in

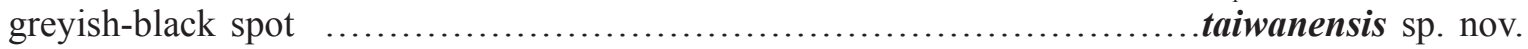

- Wing pattern dimidiate, with dark pattern restricted to anterior half of wing, extending slightly into cells br and $\mathrm{r}_{4+5}$; no discrete pattern in posterior half of wing, although posterior margin of wing broadly greyish; stump vein usually colourless and not in greyish-black spot ..... burmensis Hardy, 1973

Ichneumonopsis burmensis Hardy, 1973

Figs $1-2,7,10,13,18,20-23,25,27,31-34$

Ichneumonopsis burmensis Hardy, 1973: 133.

Ichneumonopsis burmensis - Hardy 1986: 54, 56 (key). — Drew \& Hancock 1994: 830. — Norrbom et al. 1999b: 161. — Radhakrishnan 2000: 203 (first record for India). — Kovac et al. 2006: 184. — Kovac et al. 2013: 117 (biology and immature stages).

\section{Material examined}

MYANMAR: holotype, đ̂, Mt. Victoria, Chin Hills, 1400 m, Apr. 1938, G. Heinrich leg. (BMNH); allotype, + , same data as holotype (BMNH).

INDIA: 1 9, Manipur, Churachandpur, 915 m, 10 May 1976, S. Biswas leg., no. B 44, Ghorpade Collection Bangalore, purchased by Tel Aviv University, 2002 (SMNHTAU); 1 $\curvearrowright, 2$ + $q$, Meghalaya, Nongpoh Forest, 25-28 Apr. 1980, A. Freidberg leg. (SMNHTAU).

THAILAND: all specimens were reared by D. Kovac from bamboo shoots of Pseudoxytenanthera albociliata, collected in North Thailand, Mae Hong Son, Pangmapha, near Ban Nam Rin, all deposited in SMF or SMNHTAU: larva collected 1 Dec. 2008, adult 22 May 2009 (1 đ); larva collected Nov. 2008, adult 16 May 2009 ( 1 Oे, sample 12); alk 29, probe 13, larva collected 21 Nov. 2008, puparium 27 Jan. 2008, adult 17 Mar. 2009 (1 \&, sample 29); larva collected 31 Nov. 2008, adult 17 Mar. 2009 (1 , sample 2); larva collected Nov. 2008, adult 29 May 2009 (1 đ̂, sample 13); larva collected 21 Nov. 2008, adult 29 May 2009 ( 1 §ै, sample 14); larva collected 21 Nov. 2008, adult 29 May 2009 (1 ठ̊, sample 14); 


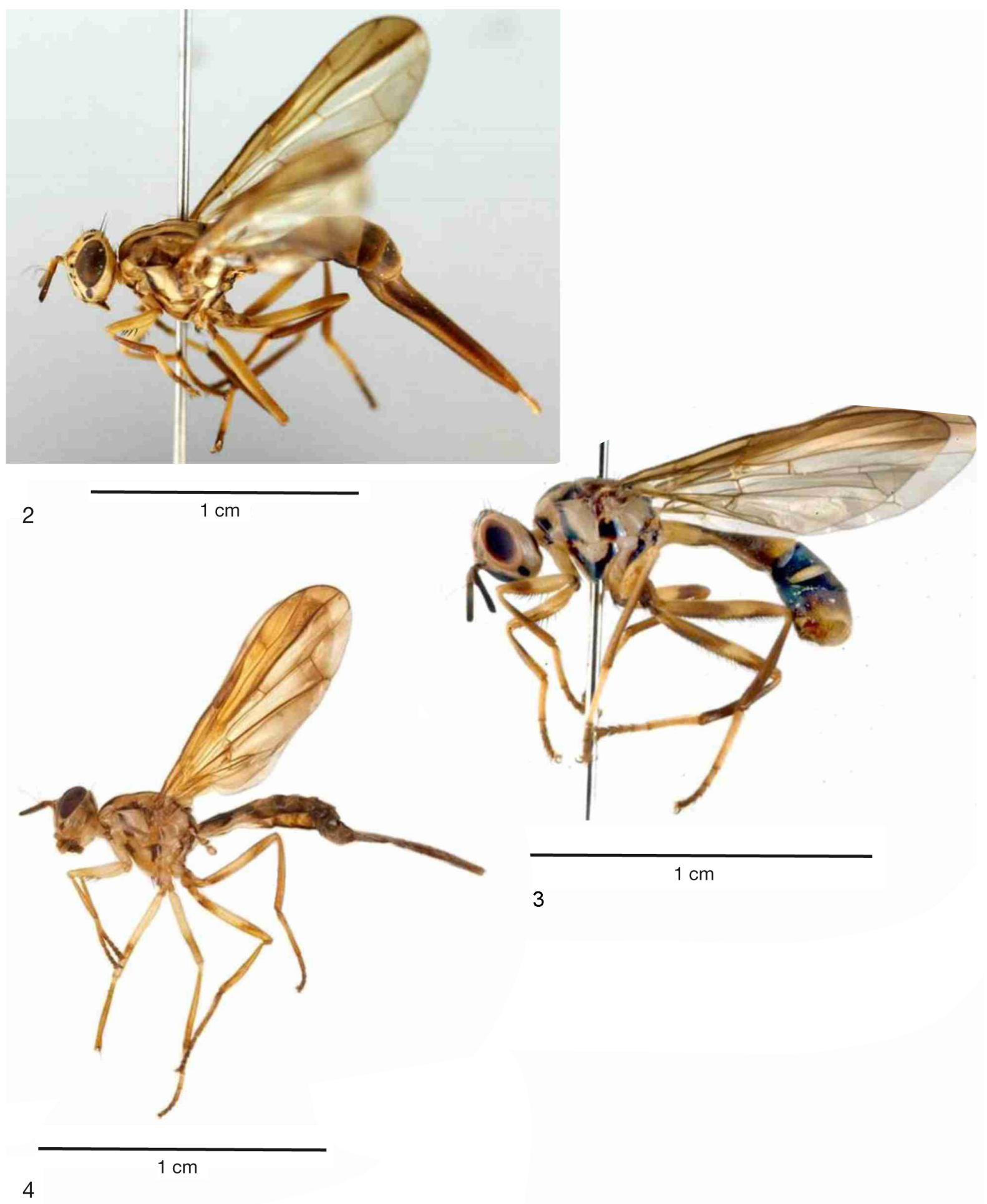

Figs 2-4. Ichneumonopsis spp., habitus. 2. I. burmensis Hardy, 1973, ․ 3. I. hancocki sp. nov., holotype, Ô. 4. I. taiwanensis sp. nov., holotype,, . 
larva collected 15 Nov. 2009, puparium 21 Dec. 2009, adult 7 Apr. 2010 (1 ठ, Z56/1/09); larva collected 15 Nov. 2009, adult 30 Apr. 2010 (1 Ô, Z49/2/09); larva collected 15 Nov. 2009, puparium 17 Dec. 2009, adult 30 Apr. 2010 (1 \&, Z55/1/09); larvae collected 28 Nov. 2009, adults 3 May 2010 (1 万, 1 q, Z57/2/09); larva collected 28 Nov. 2009, adult 7 May 2010 (1 ô, Z57/3/09); larva collected 15 Nov. 2012, adult 11 May 2013 ( 1 \&, Z68/2/12b).

\section{Redescription}

Hardy's (1973) original description is mostly adequate, requiring only a few comments and a description of the male terminalia (which is lacking in the original description).

\section{Head (Fig. 7)}

Colouration. Number of lateral facial spots varies between 2 (Hardy 1973: 133, fig. 58b) and 4, spot pattern sometimes asymmetrical; parafacial sometimes with small dark spot in addition to large dorsal spot.

Chaеtotaxy. Tiny frontal seta or enlarged setula sometimes present (more so in females) slightly dorsal to large parafacial spot.

Thorax (Figs 7, 10)

Colouration. Scutal pattern (Fig. 7) comprised of vittae best developed in dark specimens (from Thailand): lateral (notopleural) vitta (pair) entirely blackish or brownish centrally; dorsocentral vitta (pair) extending from anterior brown margin of postpronotum as nearly complete vitta (narrowly but distinctly interrupted at transverse suture) to scutoscutellar suture, and both these vittae connect by blackish transverse band along this suture; median vitta (single) narrower and paler than dorsocentral vitta, extending from scapular setae to scutoscutellar suture, also connecting to scutoscutellar band; (pair of) complete yellow submedian bands result, extending from anterior margin of scutum to blackish

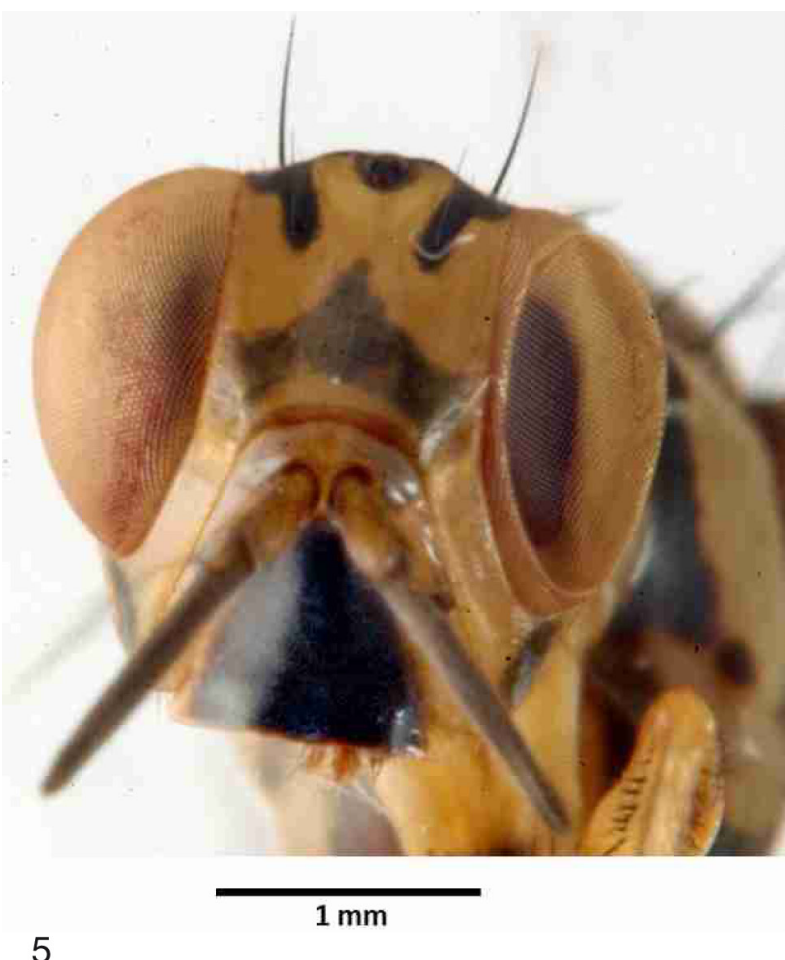

5

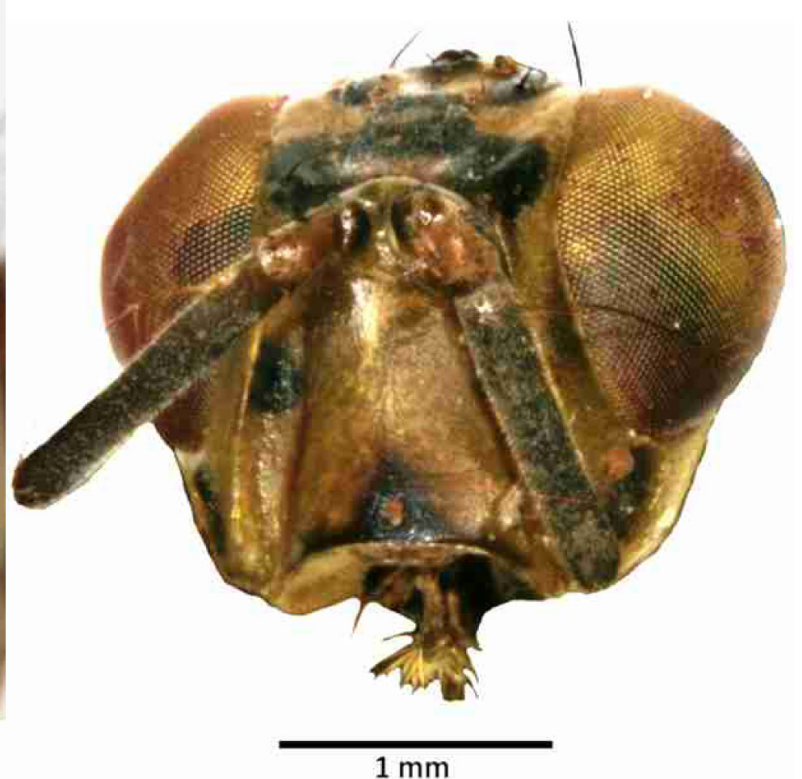

6

Figs 5-6. I. hancocki sp. nov., head, anterior view. 5. Љ๋. 6. 오. 


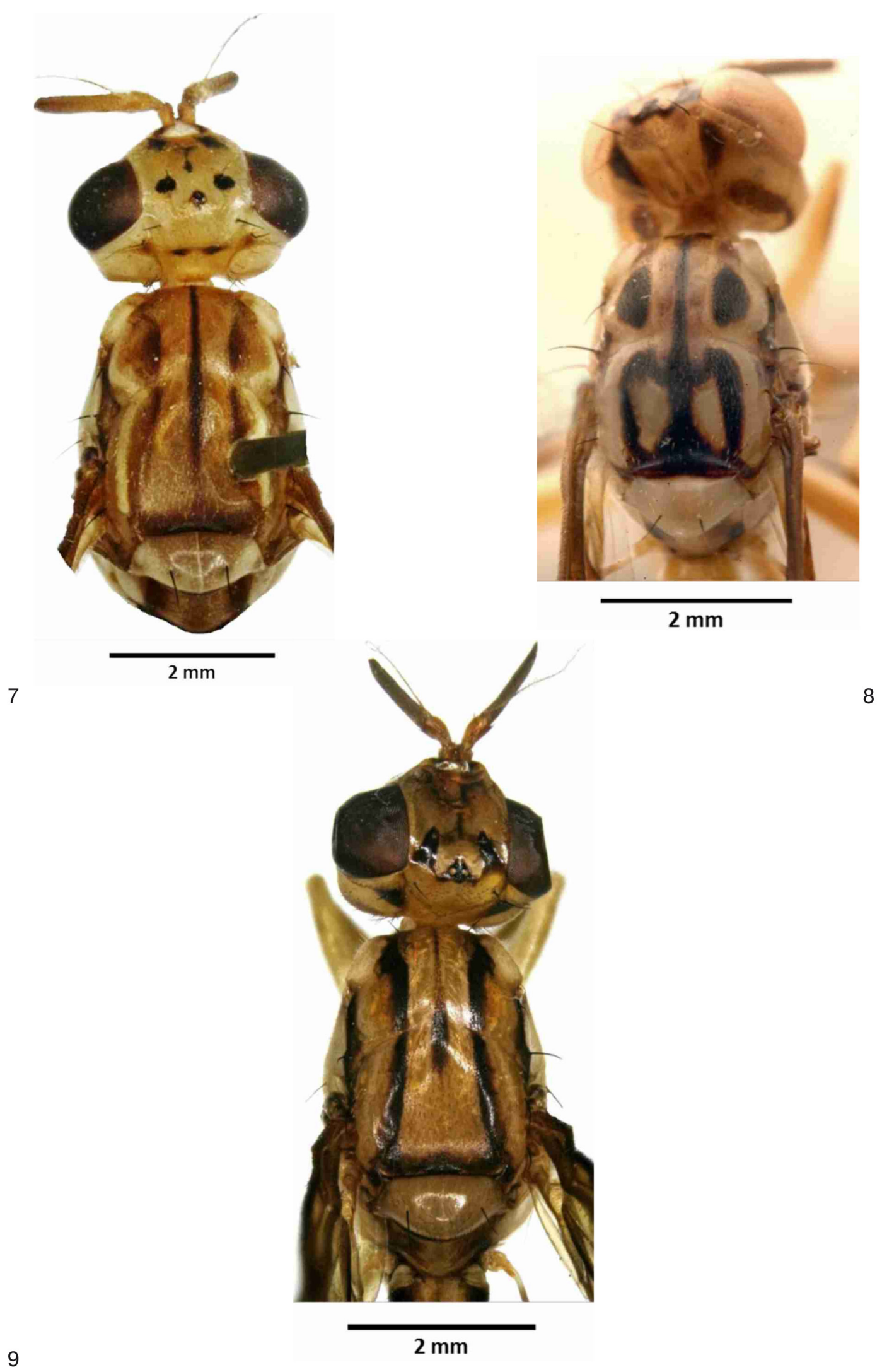

Figs 7-9. Ichneumonopsis spp., head and thorax, dorsal view. 7. I. burmensis Hardy, 1973. 8. I. hancocki sp. nov. 9. I. taiwanensis sp. nov. 
scutoscutellar band, each about as wide as dorsocentral vitta. In paler specimens (from India) dark bands much paler and reduced, mostly less contrasted with yellow background, although brownishyellow lateral vitta well contrasted with adjacent yellow areas, and narrow median vitta visible throughout its length to or almost to transverse (scutoscutellar) band. Pleural pattern (Fig. 10; best developed in dark specimens) comprised of black vertical or oblique bands and/or spots on whitish or yellowish background as follows: proepisternum black, black extending dorsally to dark area anterior to postpronotum, ventrally to proepimeron (not entirely black), and further "extending" ventrally onto forecoxa dorsobasally; anepisternum with large triangular stripe extending from posterior end of postpronotum and notopleuron to anteroventral corner of anepisternum, just beyond delicate suture extending from near this corner to anepisternal seta; katepisternum with wide "v"-like black pattern, covering most of sclerite except dorsomedially and ventrally where yellowish; posterior arm of " $\mathrm{v}$ " "extending over anepimeron, including greater ampulla; narrow sinuous black band extending vertically along posterior half of meron, around anterodorsal margin of spiracle, penetrating into ventral margin of katatergite and reaching base of halter. Postcoxal bridge sclerotized and black. In specimens from India dark pleural pattern mostly brown or dark yellow. Scutellum whitish, narrowly darkened (brownish or blackish) basally; subscutellum pale or dark yellowish, with brownish or blackish lateral and dorsal margins. Calypteres short, slightly bulging anterolaterally.

\section{Legs (Fig. 13)}

As for genus.

Wing (Fig. 18)

Pattern mostly as in Hardy (1973: 133, fig. 58d), with following additions: dark pattern along and posterior to last section of vein $\mathrm{R}_{4+5}$ distinctly darker than adjacent parts of pattern; cell bcu and surrounding yellowish.

\section{Abdomen (Figs 20-21)}

Terminalia, male (Figs 22-23, 25). Digitiform prolongation of surstylus about four times as long as wide; setae on epandrium conspicuous, similar in appearance and density to those on proctiger; nonsclerotized part of glans beyond cochleate sclerotization elongate, about 4 times as long as wide, apically with small sclerotized sclerite about $0.25-0.30$ times as long as width of cochleate complex.

Terminalia, Female (Figs 27-29). Cercal unit relatively broad, without constriction, with system of longitudinal "canals" crowded toward tip (tip of aculeus illustrated by Hardy 1973: fig. 58e); sensory

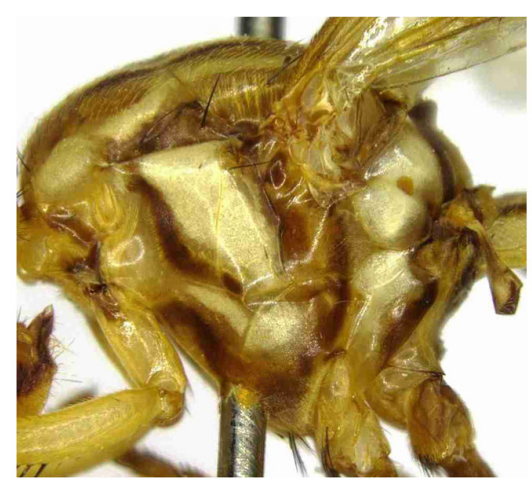

10

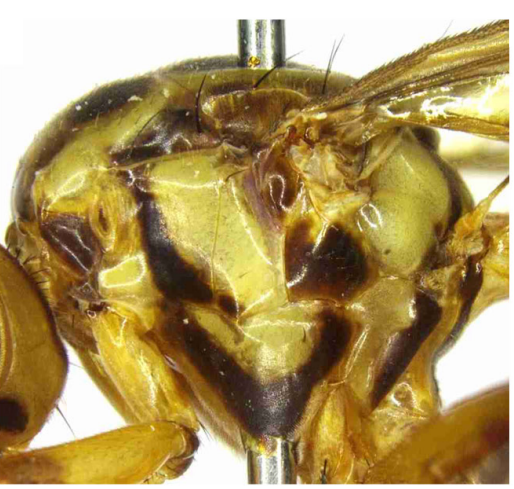

11

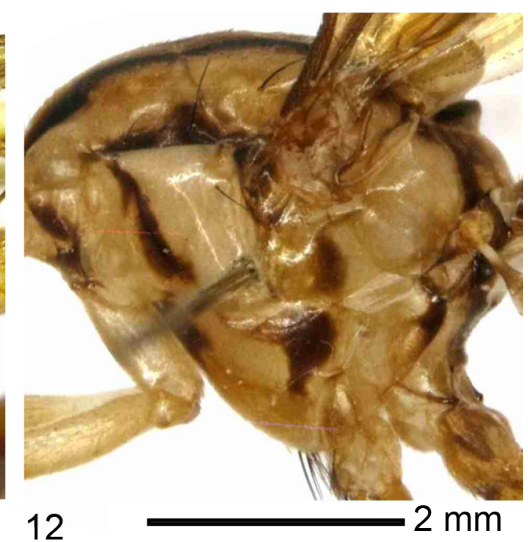

12

Figs 10-12. Ichneumonopsis spp., thorax, lateral view. 10. I. burmensis Hardy, 1973. 11. I. hancocki sp. nov. 12. I. taiwanensis sp. nov. 

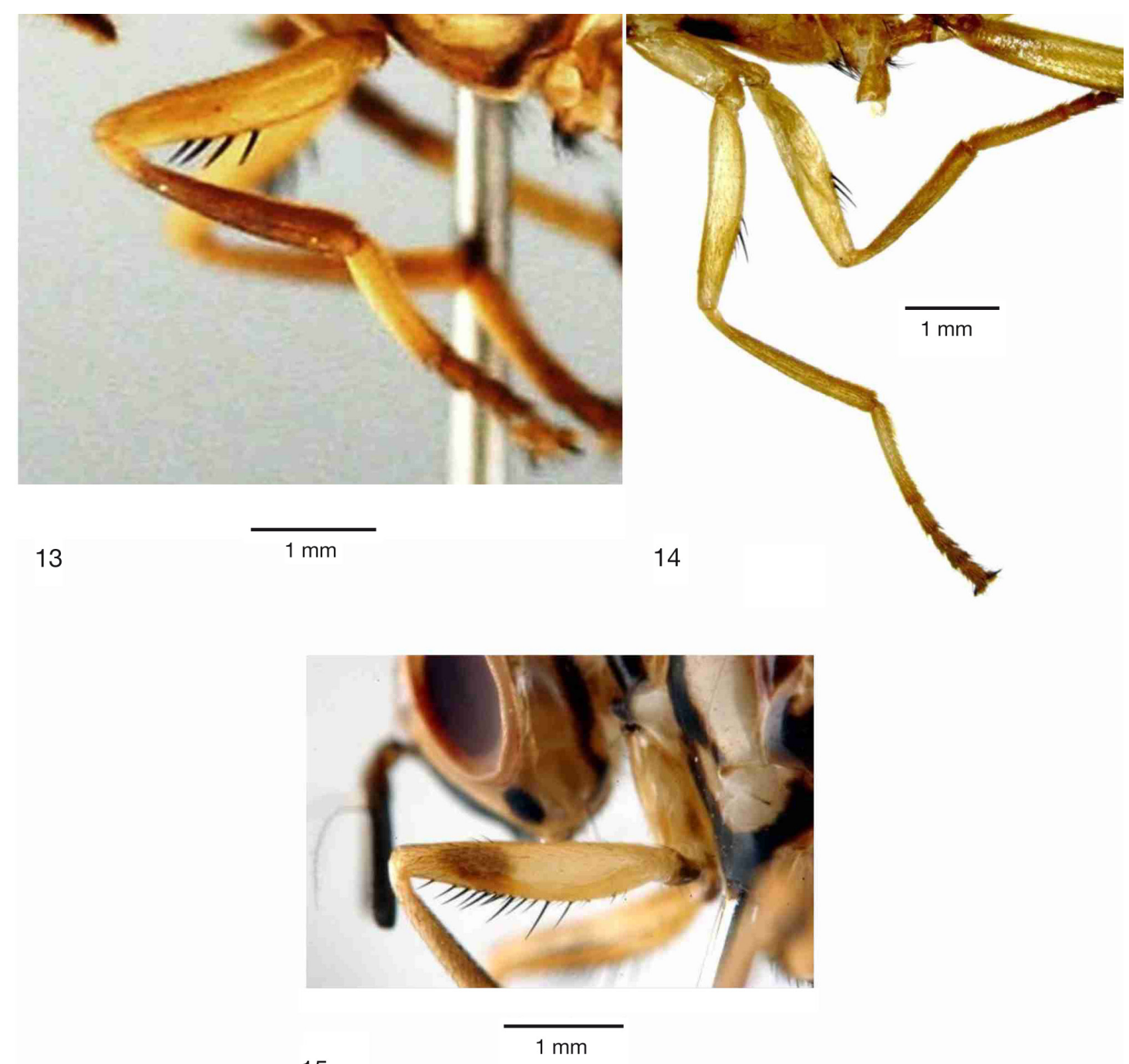

15
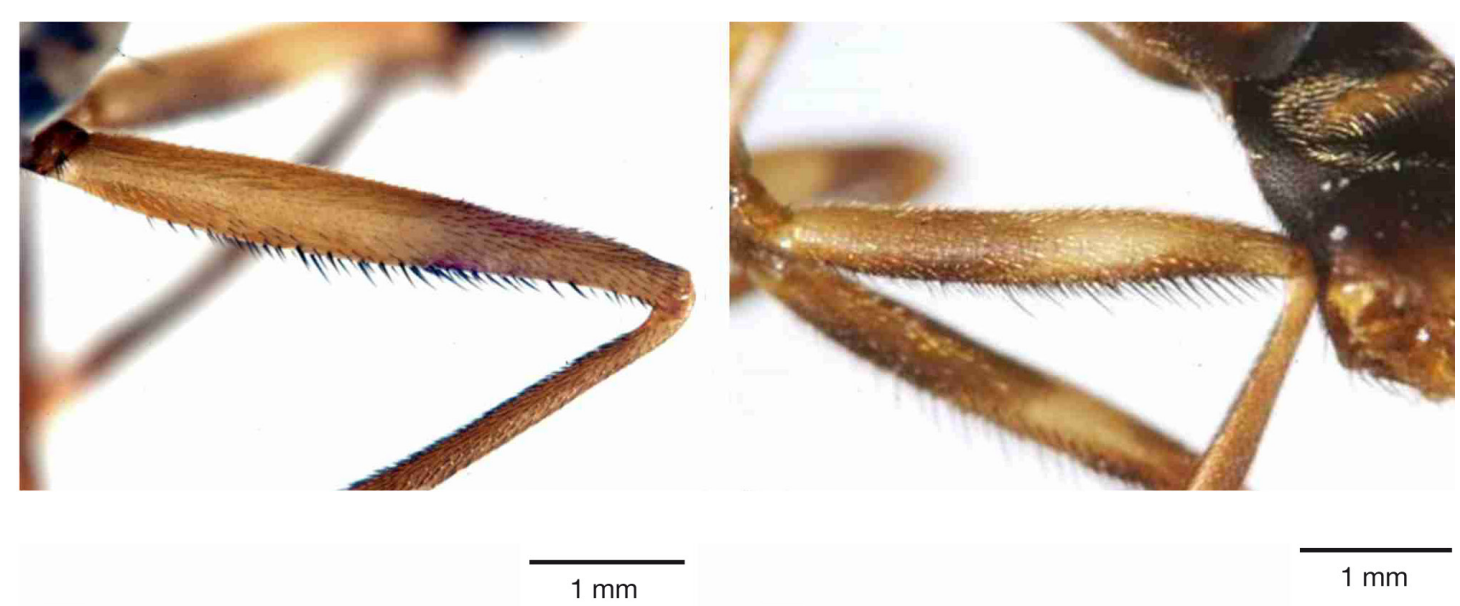

16

17

Figs 13-17. Ichneumonopsis spp., legs. 13. I. burmensis Hardy, 1973, foreleg. 14. I. taiwanensis sp. nov., foreleg. 15. I. hancocki sp. nov., foreleg. 16. I. hancocki sp. nov., midleg. 17. I. hancocki sp. nov., hindleg. 
setae short, about $0.12-0.16$ times as long as width of aculeus at this level; spermathecae illustrated and described by Hardy (1973: fig. 58c), who wrote: "Two small round spermathecae present". The spermathecae, however, were not found in our dissections.

Measurements (length, in $\mathrm{mm}$ )

Male: body: 11.5-13.5; wing: 10.0-10.6; female: body, including oviscape: 18.0-24.1; wing: 10.5-11.8; oviscape: $6.9-8.5$.

\section{Biology and immature stages (Figs 31-34)}

A detailed biological account of this species was the subject of another publication (Kovac et al. 2013). Only the following few relevant comments have been taken from that publication in order to add some perspective to the present one. In north-west Thailand I. burmensis larvae were found to develop in shoots of the bamboo Pseudoxytenanthera albociliata (Munro) Nguyen (Fig. 31). In our study area the bamboo clumps of $P$. albociliata grew in open clearings, at the edges of fields, or in secondary forest at altitudes of 600-1200 m. In addition, we have one, newly reared specimen of I. burmensis from a side branch of a bamboo shoot of Dendrocalamus strictus (Roxburgh) Nees.

Each infested bamboo shoot usually contained only one internode inhabited by a single I. burmensis larva (Fig. 33) which pupariated in a cocoon (Fig. 34). The infested internode was the $4^{\text {th }}-6^{\text {th }}$ internode below the apex. The larvae fed mainly in the lower half of the internode on the white pith found in the internode cavity, and also damaged the bamboo wall at the base of the internode. Due to these feeding activities the apical 4-5 internodes of the bamboo shoot died off and fell to the ground, with the infested internode remaining at the apex of the bamboo shoot (Fig. 32).

The fully-grown larvae usually moved to the base of the internode cavity, where they created a cocoon by tearing off strips of vascular bundles from the bamboo wall (Fig. 33) and enclosing themselves using finer bamboo particles probably mixed with frass. The larvae pupariated in the cocoon (Fig. 34) and remained there for about three months during the dry season. During that time the upper two-thirds of the infested internode broke off and fell to the ground, but the puparium usually remained in place at the tip of the bamboo shoot. However, sometimes the larvae pupariated in the upper part of the internode and then also fell with it to the ground still enclosed by the internode cavity and the cocoon.

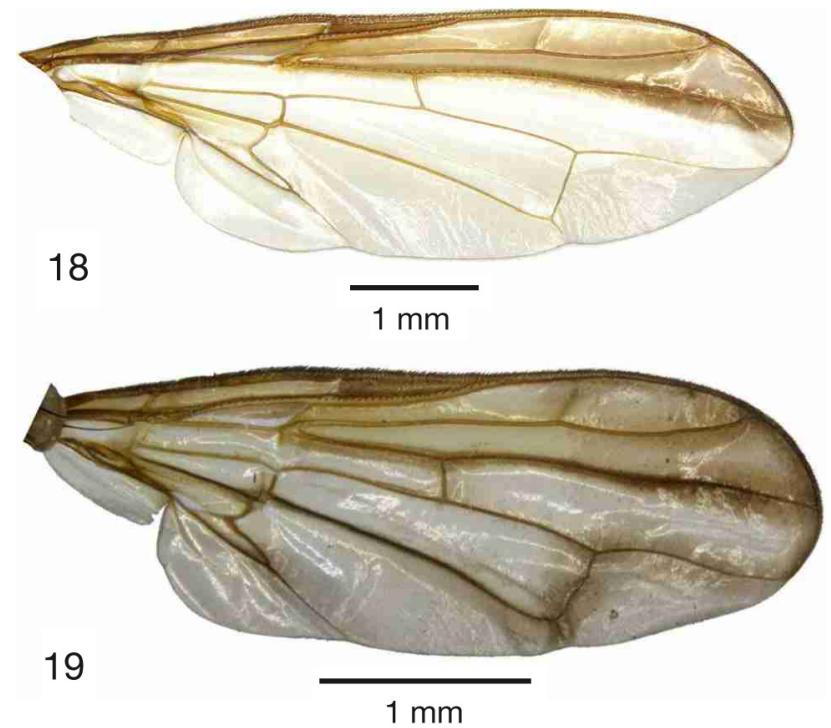

Figs 18-19. Ichneumonopsis spp., wing. 18. I. burmensis Hardy, 1973. 19. I. taiwanensis sp. nov. 
The larvae of I. burmensis were found in the field in October and November. They pupariated in November or December and the adults emerged between the end of March and beginning of May. Most (and the largest) shoots of $P$. albociliata appeared between September and November, but smaller shoots also appeared after the start of the rainy season in June and July. Combining the phenological data obtained in India and Thailand, it appears that I. burmensis is bivoltine, since the adults were collected or reared from larvae during two distinct seasons, i.e., March - May and October - November.

The bamboo microhabitat of I. burmensis is similar to that of the Gastrozonini Anoplomus rufipes Hardy, 1973. Larvae of A. rufipes also colonized a single internode of a living bamboo shoot, namely the $5^{\text {th }}-6^{\text {th }}$

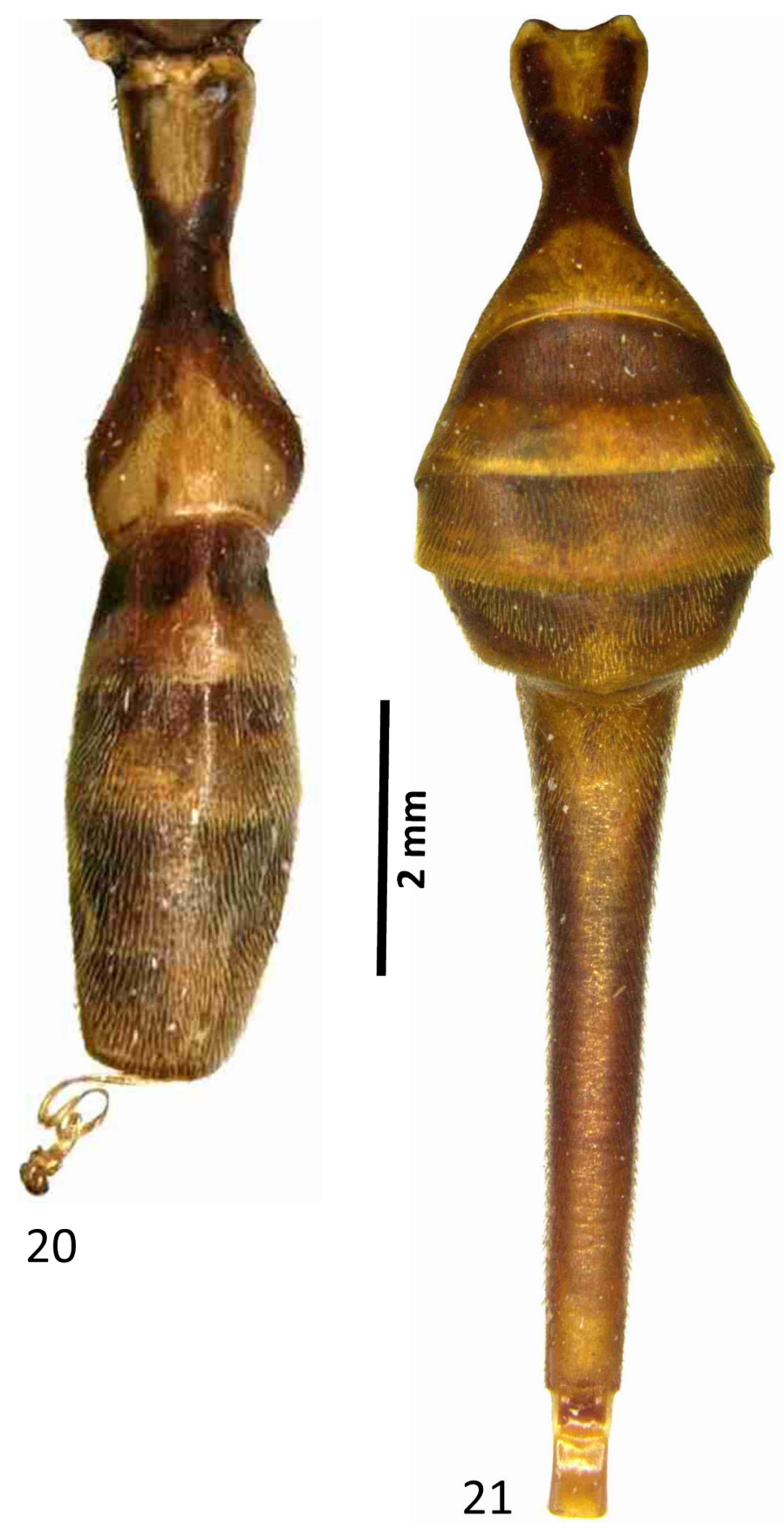

Figs 20-21. Ichneumonopsis burmensis Hardy, 1973, abdomen, dorsal view. 20. §̊. 21. ․ . 
internode below the apex (Kovac 2015). However, they generally inhabited a larger bamboo species, Cephalostachyum pergracile Munro, and there the infested internodes contained up to 40 larvae. Unlike A. rufipes and other Gastrozonini, the larvae of I. burmensis did not skip and they pupariated in the internode and not in the soil (thereby removing the need to skip).

\section{Distribution}

India (Meghalaya, Manipur), Myanmar and Thailand (Mae Hong Son).

\section{Comments}

Ichneumonopsis burmensis was known from eastern India (Meghalaya, Manipur: Drew \& Hancock 1994, Radhakrishnan 2000), western Myanmar (Hardy, 1973) and northwest Thailand (Kovac et al. 2013 and the present publication). It is probably more widespread than indicated, and we assume that it occurs at least in countries where the associated bamboo species grows, i.e., in Nepal, India, Bangladesh, Myanmar (eastern and southern parts), Thailand, Laos and Vietnam (Ohrenberger 1999). The Thai population is darker than the Indian population.

Ichneumonopsis hancocki sp. nov. urn:1sid:zoobank.org:act:0189FDE4-39B5-4F52-9C15-7777015C5006

Figs 1, 3, 5-6, 8, 11, 15-17

\section{Diagnosis}

This species is similar to I. burmensis, differing from it primarily in its smaller size, darker colouration (e.g., face of male mostly or entirely black, compared with predominantly yellow in I. burmensis) and in all three femora being extensively spinose in both sexes (only forefemur with only about four spines in I. burmensis). It is also similar to I. taiwanensis sp. nov. in its relatively small size, but it differs from this species by the more restricted dimidiate wing pattern and by all femora being spinose (wing pattern extended-dimidiate and only forefemur spinose in I. taiwanensis sp. nov.).

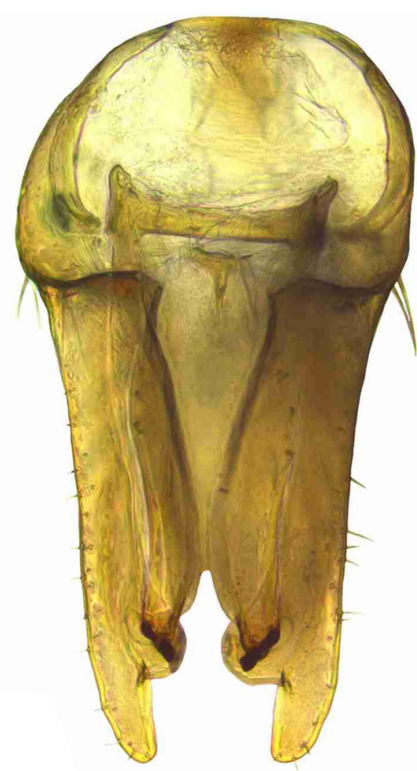

22

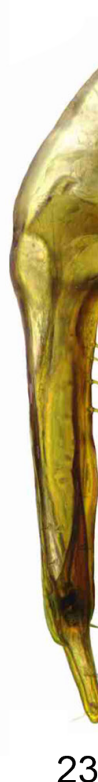

23

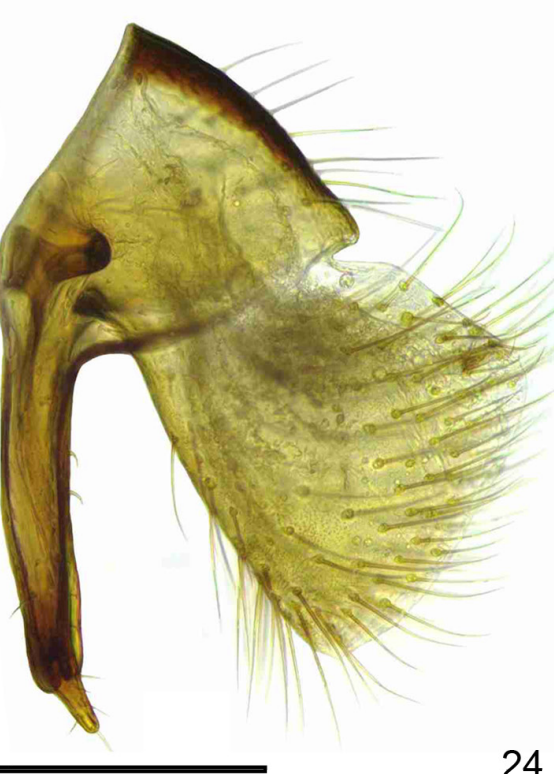

24

Figs 22-24. Ichneumonopsis spp., epandrium. 22. I. burmensis Hardy, 1973, anterior view. 23. I. burmensis Hardy, 1973, lateral view. 24. Ichneumonopsis taiwanensis sp. nov., lateral view. 


\section{Etymology}

This species is named after D.L. Hancock, a friend and prolific tephritidologist, who contributed much to the knowledge on Gastrozonini, including useful revisions of this group (Hancock 1999; Hancock \& Drew 1999).

\section{Material examined}

\section{Holotype}

MALAYSIA: ${ }^{\Uparrow}$, Selangor, “Old Gombak Road”, on stump of freshly cut bamboo shoot of Gigantochloa scortechinii, 17 Oct. 2003, P. Dohm leg., pinned directly and in good condition [M03/1096] (SMF).

\section{Paratype}

MALAYSIA: 1 q, State of Selangor, Ulu Gombak, W Malaysia, 4 Jun. 1970, James E. Tobler leg. [Genus and sp. prob. new, det D.E Hardy 1985. // Related to Ichneumonopsis] original label, written with pencil on paper (CAS).

\section{Description}

Only differences from I. burmensis are noted.

\section{Head}

Colouration. Ocellar and orbital spots united; frontal, genal and occipital dark spots similar to those of I. burmensis, although some of these less obvious in female paratype; male face with one lateral spot, and entire large bulging triangular central area black; parafacial spots lacking; female face only with ventral margin blackish, extending slightly dorsomedially as small triangle.

\section{Thorax}

COLOURATION. Dark dorsocentral vitta divided into two parts: short and wide oval presutural spot clearly separated from postsutural vitta-like section; these sections both unite along scutoscutellar suture and at level of supra-alar seta, thus enclosing (pair of) yellow oval spots between dorsocentral and median vittae; median vitta distinctly broadened posteriorly, particularly in posterior quarter where it merges

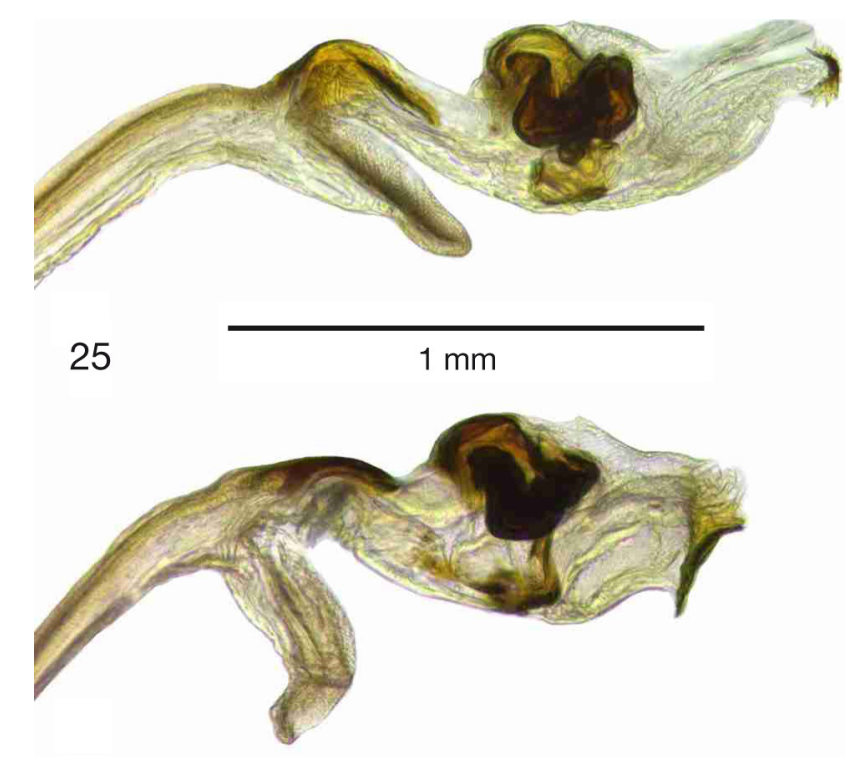

26

Figs 25-26. Ichneumonopsis spp., glans. 25. I. burmensis Hardy, 1973. 26. I. taiwanensis sp. nov. 


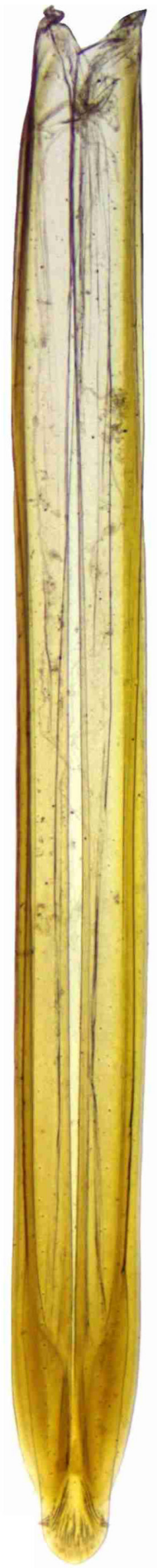

27

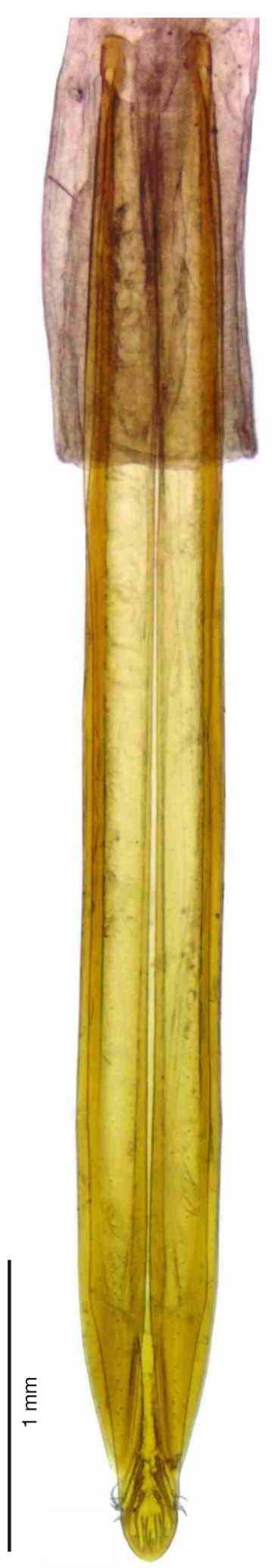

28

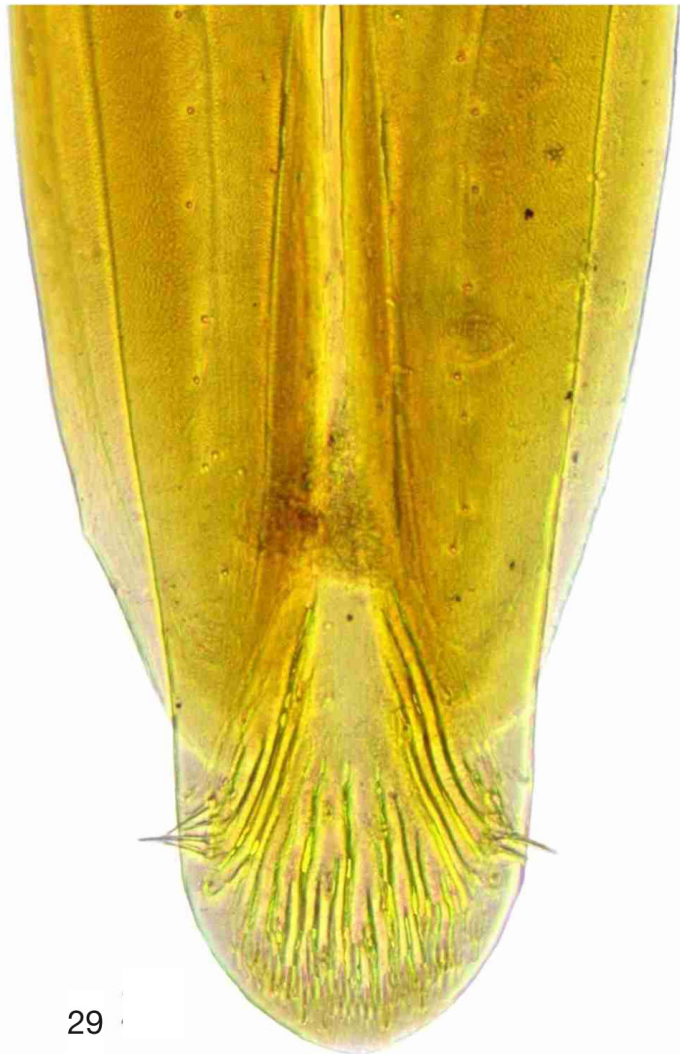

$\varepsilon$
$\varepsilon$
10
0

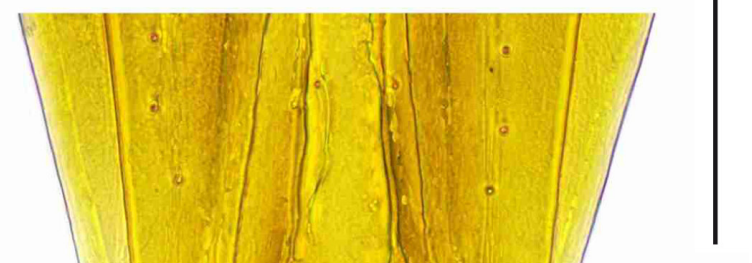

Figs 27-30. Ichneumonopsis spp., aculeus. 27. I. burmensis Hardy, 1973, entire aculeus. 28. I. taiwanensis sp. nov., entire aculeus. 29. I. burmensis Hardy, 1973, aculeus apex. 30. I. taiwanensis sp. nov., aculeus apex. 


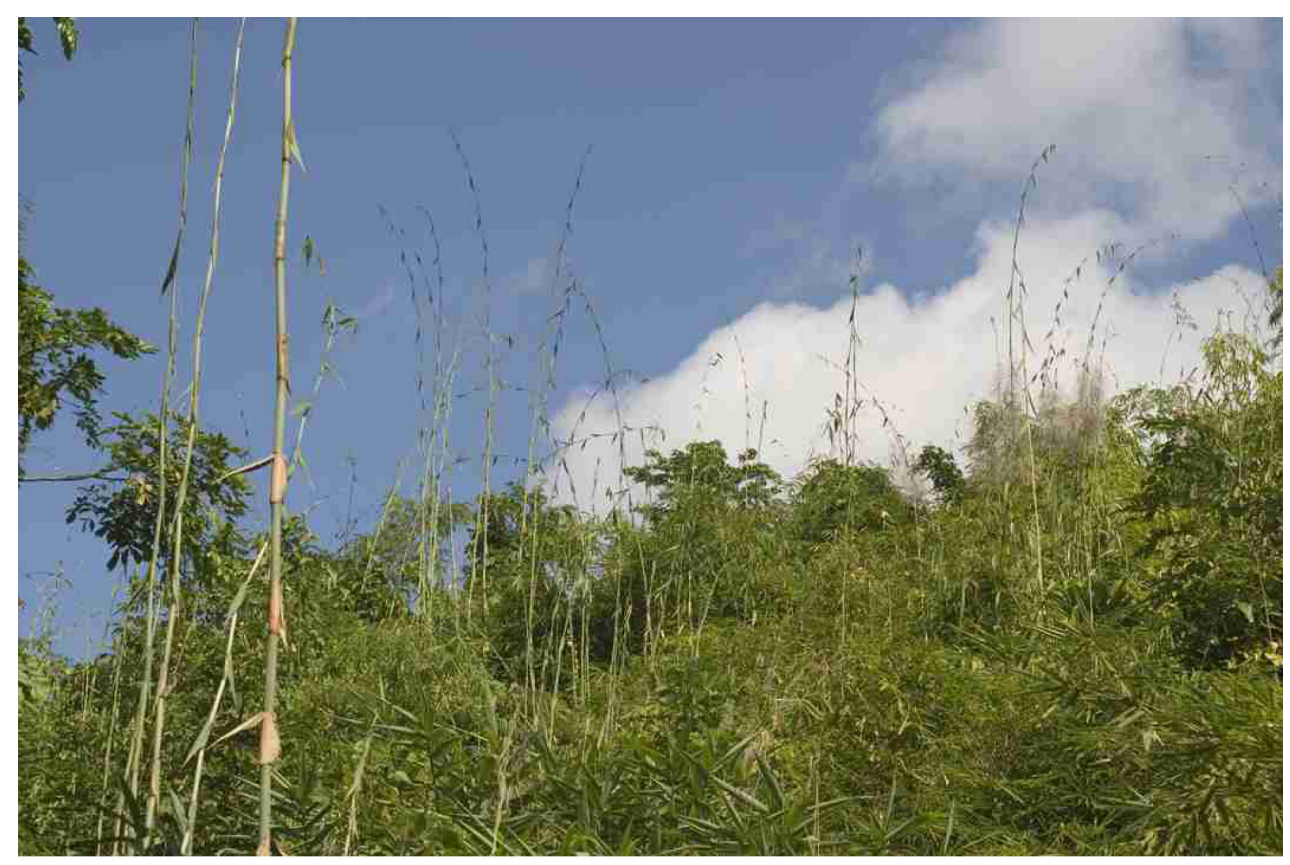

31
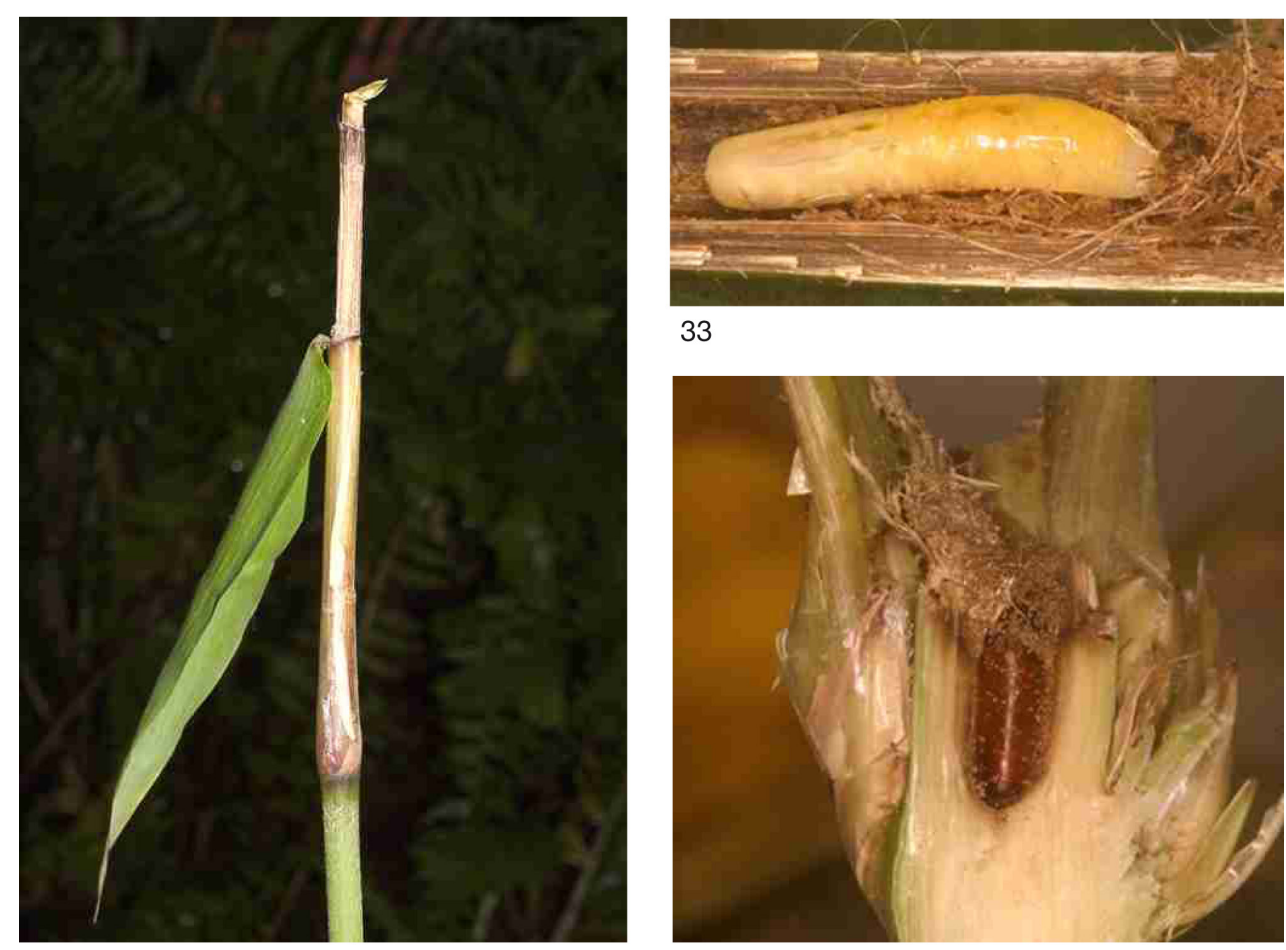

33

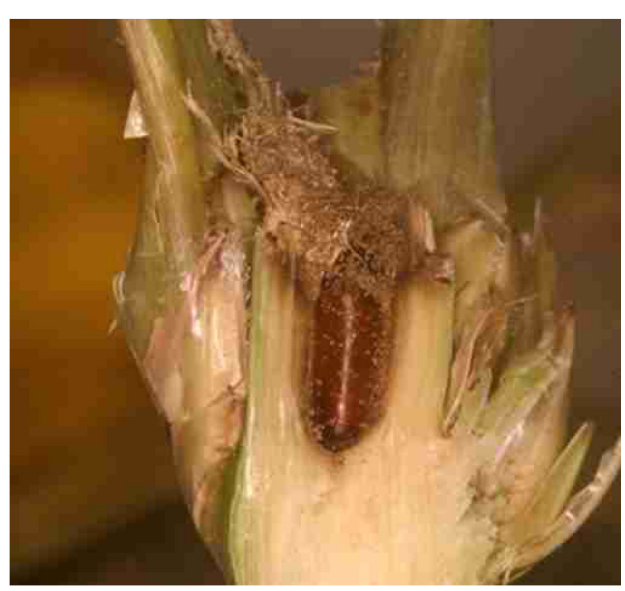

32

34

Figs 31-34. Ichneumonopsis burmensis Hardy, 1973, biological traits. 31. Bamboo shoots of the host plant, Pseudoxytenanthera albociliata, at the edge of an abandoned field in northern Thailand in November. The shoots are 2-5 $\mathrm{m}$ tall and up to $2 \mathrm{~cm}$ wide at the base. 32. Bamboo internode (ca $7 \mathrm{~mm}$ wide) infested by an I. burmensis larva. The internode is located at the tip of the bamboo shoot, because the apical 4-5 internodes have died and fallen to the ground. 33. A fully-grown I. burmensis larva (length ca $14 \mathrm{~mm}$ ) that has started to bite off strips of vascular bundles from the bamboo shoot wall (on the right) in order to create a cocoon. 34. I. burmensis puparium (length ca $8 \mathrm{~mm}$ ) located in the internode cavity at the base of the infested internode. The upper part of the internode has broken off. Side branches growing from the basal bud were partly removed. 
with black transverse scutoscutellar band. Pleural pattern as in I. burmensis, although dark extension "into" forecoxa lacking and forecoxa entirely yellow.

\section{Legs}

All femora spinose both anteroventrally and posteroventrally (spines mixed with regular setae), although posteroventral row with generally longer spines, and rows of spines denser and longer in male than in female, extending in male along distal half of femur or more, whereas in female extending along distal 0.33 almost to middle of femur. Male (only approximate numbers as spines tend to grade to regular setae): forefemur: 11-12 spines posteroventrally and 9-10 spines anteroventrally; midfemur: 20 and 15, respectively; hindfemur: 20 and 20, respectively; in addition ventral surface of midfemur and hindfemur centrally with additional setae or spines interspaced between two major rows. Female: spines considerably shorter than in male and more difficult to count, especially as tibiae are folded over respective femora, hiding some spines. Female's numbers appear to be half of male numbers or even fewer. Colouration: forecoxa entirely yellow; forefemur with incomplete brownish ring at distal 0.4; foretibia, and also other tibiae, entirely brown or brownish; foretarsus, and also other tarsi, brownish, except metatarsi yellow; midfemur at nearly distal half with incomplete ring, more distinct at posterior aspect; hindfemur brown to blackish at approximately basal half, more obvious ventrally, with yellow gap dorsally; similar, but smaller and paler incomplete ring at distal 0.33 of femur.

\section{Wing}

Venation. Posterodistal lobe of cell bcu 1.5-2.0 times as long as vein $\mathrm{A}_{1}+\mathrm{Cu}_{2}$.

PATTERn. Marginal band uniformly yellow, not particularly darker around apical section of vein $\mathrm{R}_{4+5}$.

\section{Abdomen}

As for genus; terminalia not dissected.

Measurements (length in $\mathrm{mm}$ ) Male: body: 11.0; wing: 10.2; female: body, including oviscape: 16.8; wing: 10.0; oviscape: 7.3.

\section{Distribution}

West Malaysia.

\section{Comments}

Being singletons, the holotype and paratype were not dissected. The I. hancocki sp. nov. male was collected by Patrick Dohm on a freshly cut bamboo shoot of Gigantochloa scortechinii. The bamboo shoot was about $2.5-3.5 \mathrm{~m}$ high and the upper part of the shoot (ca $80 \mathrm{~cm}$ long) was cut off and placed on the ground. The $I$. hancocki sp. nov. male alighted at the cut surface of the upright bamboo stump about half an hour after the apex of the shoot was cut off.

Ichneumonopsis taiwanensis $\mathrm{sp}$. nov. urn:1sid:zoobank.org:act:D6D4B9D9-4053-4035-B51F-49D7BD3AD822

Figs 1, 4, 9, 12, 14, 19, 24, 26, 28, 30

\section{Diagnosis}

This species is similar to I. burmensis in having only the forefemur spinose, differing from it primarily in having 2-3 spines (but see Legs below) posteroventrally on forefemur (2-5, usually 4 spines in I. burmensis), and in the more extensive wing pattern, extending into the posterior part of the wing (wing pattern dimidiate and restricted to anterior half of wing in I. burmensis). I. taiwanensis sp. nov. differs 
from I. hancocki sp. nov. by the more extensive wing pattern, (dimidiate in I. hancocki sp. nov.) and by having only the forefemur spinose (all femora spinose in $I$. hancocki sp. nov.).

\section{Etymology}

This species is named after the country where the types were found, Taiwan.

\section{Material examined}

\section{Holotype}

TAIWAN: + , Nantu, Yuchi, colour trap (see Comments), 24 Apr. 2000, C.Y. Lee leg., double mounted, minutien pin on a block of foam and in good condition (most of the right antenna is missing) (NTU).

\section{Paratypes}

TAIWAN: same collection data as holotype, but different dates and sometimes gender: $1 \curvearrowright, 2$ 우, 9 Jul. 2000; 1 \&, 7 May 2000; 1 §̂, 21 May 2000 (NTU, 3 specimens; SMNHTAU, 1 specimen; SMF, 1 specimen).

\section{Description}

Only differences from I. burmensis are noted.

\section{Head}

Colouration. No discrete lateral facial spots present, although ptilinal suture between face and parafacial somewhat blackened, occasionally broadened into indistinct asymmetrical ventral dark spots; parafacial with barely distinct blackish spot aligned slightly ventral to base of antenna.

Снаетотаху. Frontal setae 1 or 2, anterior seta moderately long; posterior seta present only in one male, setula-like, barely distinguishable from adjacent setulae.

\section{Thorax}

Colouration. Dark lateral (notopleural) vitta mostly dark brown, slightly brownish centrally; dorsocentral vitta more narrowly interrupted at transverse suture; median vitta short, extending across transverse fissure, about as long as width of yellow gap between both dorsocentral vittae; the two yellow submedian bands united along most of their length. Pleural pattern generally as in I. burmensis, although greatly reduced both in intensity and size of dark areas, but all parts of pattern still represented by smaller black or blackish areas (a kind of transition form between dark and pale specimens of I. burmensis): katepisternal "v", for example, reduced into two relatively small black spots comprising apices of arms of "v"), although connecting corner of "v" distinctly yellow, but obvious.

\section{Legs}

Total number of spines and setulae on forefemur 2-6, total number of only large spines $2-5$ (average 3.2). Colouration: varies between entirely yellow, often with some vaguely darker areas, to slightly darker pattern including brownish traces of femoral rings, brownish-yellow tibiae, and brownish three or more tarsomeres.

\section{Wing}

PATTERN. Similar to that of I. burmensis, although more extensive; pattern at anterior half of wing includes dark (greyish-black) spot over spur vein across cell $\mathrm{r}_{1}$; pattern at posterior part of wing comprises mainly blackish band over distalmost section of vein $\mathrm{M}$ and arm of this band over crossvein DM-Cu, blackish vein $\mathrm{Cu}_{1}$ and its immediate vicinity and less discrete blackish spot over distal half of posterodistal lobe of cell bcu; remaining posterior half of wing appearing greyish or hyaline, depending on the light. 


\begin{abstract}
Abdomen
Terminalia, male (Figs 24, 26). Digitiform prolongation of surstylus about twice as long as wide; setae on epandrium not conspicuous, shorter, paler and sparser than those on proctiger; non-sclerotized part of glans beyond cochleate sclerotization short, about as long as wide, apically with large sclerotized sclerite about 0.6 times as long as width of cochleate complex of glans.
\end{abstract}

Terminalia, female (Figs 28, 30). Cercal unit with slight constriction aligned with sensory setae; setae clearly larger than those of I. burmensis, about 0.25 times as long as width of aculeus at this level; system of longitudinal "canals" crowded along margin from base to tip.

Measurements (length, in $\mathrm{mm}$ )

Male: body: 12.4; wing: 10.9; female: body, including oviscape: 13.8-16.8; wing: 8.4-11.5; oviscape: 4.6-6.6.

\title{
Comments
}

This species was discovered in Taiwan by Hong-Yih Chang and treated in his dissertation (Chang 2001). Altogether, eleven specimens were collected by C.Y. Lee in the Nantu County (ca $120^{\circ} 50^{\prime}-20^{\circ} 59^{\prime}$ E, $23^{\circ} 49^{\prime}-23^{\circ} 66^{\prime} \mathrm{N}$, altitude $650-740 \mathrm{~m}$ ) by using colour sticky traps. However, only six specimens were found at the Department of Entomology at the National Taiwan University. The specimens were collected near cultivated bamboo areas containing mainly Dendrocalamus latiflorus Munro (local name: Ma Bamboo), and some Phyllostachys makinoi Hayata (Makino Bamboo) and P. edulis (Carrière) J. Houzeau de Lehaie (Mao Bamboo). Like many other species described from Taiwan (Norrbom et al. 1999b), this species can be expected to be a Taiwan endemic.

\section{Discussion}

The accumulation of scientific knowledge and data is usually a gradual and painstaking process, and analysis and conclusions based on the accumulated data constitute further steps in scientific thinking that are often involved in debate and reconsiderations. The current study is no exception, and Ichneumonopsis represents an interesting example of biotaxonomy studies and the concurrent debate. Hence, the purpose of this brief discussion is to summarize the current taxonomic status of this genus and to offer additional approaches. Hardy (1973) described Ichneumonopsis and placed it in the Adramini. Since then the taxonomic position of Ichneumonopsis has become a matter of mini-debate between fruit fly researchers. Hancock (1986), Drew \& Hancock (1994) and Drew \& Romig (2013) included Ichneumonopsis within the Dacini, whereas others (Norrbom et al. 1999b; Kovac et al. 2006) placed it in the Gastrozonini. None of the above workers supported a return to the Adramini, an assignment recognized by all relevant experts as incorrect. The Dacini constitutes a large group, with ca 700 described spp. (e.g., Drew \& Romig 2013; White 2006). It is also a very homogenous group, with several unique and distinctive synapomorphies that are highly consistent, almost without exceptions. The wing venation provides at least two synapomorphies unknown in other tephritids: a (usually) long posterodistal lobe of cell bcu, sometimes extending nearly to wing margin (shorter in other tephritids); cell bm about twice as wide as cell bcu (about as wide as cell bcu in all other tephritids); and males and females also have unique terminalia. None of these apomorphies occur in Ichneumonopsis. However, several abdominal synapomorphies (female's T6 greatly reduced and hidden below T5; male often with a pecten of setae posterolaterally on T3, probably used for audible stridulation, and usually with a pair of large depressed areas (ceromata) on T5, probably secreting pheromones) that occur in Dacus and Bactrocera are, as in Ichneumonopsis, absent in the primitive Dacini genus Monacrostichus. Kovac et al. (2013), however, have provided convincing biological evidence that at least one species of Ichneumonopsis develops in bamboo host plants, while collection data also suggests a bamboo relationship in the other two species. 
It is worth noting that bamboo species are the hosts of most Gastrozonini but only of some Acanthonevrini (where decaying tissue is generally used). Although Ichneumonopsis is morphologically an atypical gastrozonine, it still shares the somewhat weak synapomorphies of that group (antenna with spinelike setulae on pedicel, and arista plumose, with long rays; aculeus broad and flat). Conversely, it does not share any of the distinctive synapomorphies of the Dacini, or the single consistent apomorphy of the Adraminae (setulose pleurotergum), and it also does not share the rather weak apomorphies of the Acanthonevrini, some of which breed in bamboo. In our opinion, these accumulated data together comprise convincing evidence that Ichneumonopsis is a gastrozonine and not, as suggested by Hancock (1986) and Drew \& Hancock (1994), a primitive dacine. A phylogenetic molecular study of the Gastrozonini may help further to resolve this debate.

\section{Acknowledgments}

We are grateful to the curators of the collections mentioned in the Introduction for allowing us to study specimens under their care. We are also grateful to Patrick Dohm for allowing us to describe a new species based on a specimen that he collected, to Decha Wiwatwitaya and Rosli Hashim for support in Thailand and Malaysia, respectively, to Tania Novoselsky, Elizabeth (Liz) Morgulis and Levona Bodner for helping us with the photography, to David L. Hancock, Allen L. Norrbom, Liz Morgulis and Levona Bodner for their comments on an earlier draft of the manuscript, and to Naomi Paz for her linguistic suggestions.

\section{References}

Chang H.Y. 2001. Species Diversity and Seasonal Fluctuations of Fruit Flies (Diptera: Tephritidae) in Bamboo Stands in Northern and Central Taiwan. Ph.D. dissertation, Graduate Institute of Plant Pathology and Entomology, National Taiwan University, Taipei, Taiwan. [in Chinese]

Copeland R.S. 2007. On the occurrence of Bistrispinaria, grass-breeding fruit flies (Diptera, Tephritidae), in Kenya, with an addition to the tephritid checklist of Kakamega Forest. Journal of East African Natural History 96: 95-102. https://doi.org/10.2982/0012-8317(2007)96[95:OTOOBG]2.0.CO;2

Drew R.A.I. \& Hancock D.L. 1994. Revision of the tropical fruit flies (Diptera: Tephritidae: Dacinae) of south-east Asia. I. Ichneumonopsis Hardy and Monacrostichus Bezzi. Invertebrate Taxonomy 8: 829838.

Drew R.A.I. \& Romig M.C. 2013. Tropical Fruit Flies (Tephritidae: Dacinae) of South-East Asia: Indomalaya to North-West Australasia. CABI, Wallingford and Boston.

Hancock D.L. 1986. Classification of the Trypetinae (Diptera: Tephritidae), with a discussion of the Afrotropical fauna. Journal of the Entomological Society of Southern Africa 49 (2): 275-305.

Hancock D.L. 1999. Grass-breeding fruit flies and their allies of Africa and Asia (Diptera: Tephritidae: Ceratitidinae). Journal of Natural History 33: 911-948. https://doi.org/10.1080/002229399300155

Hancock D.L. \& Drew R.A.I. 1999. Bamboo-shoot fruit flies of Asia (Diptera: Tephritidae: Ceratitidinae). Journal of Natural History 33: 633-775. https://doi.org/10.1080/002229399300164

Hardy D.E. 1973. The Fruit Flies (Tephritidae - Diptera) of Thailand and Bordering Countries. Pacific Insects Monographs 31, Bishop Museum, Honolulu.

Hardy D.E. 1986. The Adramini of Indonesia, New Guinea and adjacent islands (Diptera: Tephritidae: Trypetinae). Proceedings of the Hawaiian Entomological Society 27: 53-78.

Kovac D. 2015. Reproductive behavior and basic biology of the Oriental bamboo-inhabiting Anoplomus rufipes and a comparison with frugivorous Dacinae fruit flies. Insects 6 (4): 869-896. https://doi. org/10.3390/insects6040869 
Kovac D., Dohm P., Freidberg A. \& Norrbom A.L. 2006. Catalog and revised classification of the Gastrozonini (Diptera: Tephritidae: Dacinae). In: Freidberg A. (ed.) Biotaxonomy of Tephritoidea. Israel Journal of Entomology 35-36: 163-196.

Kovac D., Freidberg A. \& Steck G. 2013. Biology and description of the third instar larva and puparium of Ichneumonopsis burmensis Hardy (Diptera: Tephritidae: Dacinae: Gastrozonini), a bamboo-breeding fruit fly from the Oriental region. The Raffles Bulletin of Zoology 61 (1): 117-132.

McAlpine J.F. 1981. Morphology and terminology - adults. In: McAlpine J.F., Peterson B.V., Shewell G.E., Teskey H.J., Vokeroth J.R. \& Wood D.M. (coordinators). Manual of Nearctic Diptera, Vol. 1: 9-63. Agriculture Canada Monograph 27, Ottawa.

Norrbom A.L., Carroll L.E. \& Freidberg A. 1999a. Status of knowledge. In: Thompson F.C. (ed.) Fruit Fly Expert Identification System and Systematic Information Database: 9-48. Myia 9, Backhuys, Leiden.

Norrbom A.L., Carroll L.E., Thompson F.C., White I.M. \& Freidberg A. 1999b. Systematic database of names. In: Thompson F.C. (ed.) Fruit Fly Expert Identification System and Systematic Information Database: 65-251. Myia 9, Backhuys, Leiden, and Diptera Data Dissemination Disk (CD-ROM).

Ohrenberger D. 1999. The Bamboos of the World: Annotated Nomenclature and Literature of the Species and the Higher and Lower Taxa. Elsevier Science, Amsterdam, Lausanne, New York, Oxford, Shannon, Singapore and Tokyo.

Radhakrishnan C. 2000. Ichneumonopsis burmensis Hardy (Tephritidae: Diptera: Insecta), a new record from India. Records of the Zoological Survey of India 98 (1): 203-204.

White I.M. 2006. Taxonomy of the Dacina (Diptera: Tephritidae) of Africa and the Middle East. African Entomology, Memoir 2, Entomological Society of Southern Africa, Hatfield, South Africa.

White I.M., Headrick D.H., Norrbom A.L. \& Carroll L.E. 1999. Glossary. In: Aluja M. \& Norrbom A.L. (eds) Fruit Flies (Tephritidae): Phylogeny and Evolution of Behavior: 881-924. CRC, Boca Raton, FL.

Manuscript received: 24 May 2016

Manuscript accepted: 24 August 2016

Published on: 9 May 2017

Topic editor: Gavin Broad

Desk editor: Kristiaan Hoedemakers

Printed versions of all papers are also deposited in the libraries of the institutes that are members of the EJT consortium: Muséum national d'Histoire naturelle, Paris, France; Botanic Garden Meise, Belgium; Royal Museum for Central Africa, Tervuren, Belgium; Natural History Museum, London, United Kingdom; Royal Belgian Institute of Natural Sciences, Brussels, Belgium; Natural History Museum of Denmark, Copenhagen, Denmark; Naturalis Biodiversity Center, Leiden, the Netherlands; Museo Nacional de Ciencias Naturales-CSIC, Madrid, Spain; Real Jardín Botánico de Madrid CSIC, Spain. 